\title{
Novel Lipid Indices as a Better Marker of Cardiovascular Disease Risk in Postmenopausal Women
}

\author{
${ }^{1}$ Muruga Sirigere, ${ }^{2} \mathrm{~S}$ Meera
}

\section{ABSTRACT}

Introduction: Cardiovascular disease (CVD) is the major leading cause of mortality in men and women around the globe. The incidence of CVD increases with age in both the sexes, whereas it has been noted that there is a marked increase in risk among women after menopause. The hormonal changes associated with the menopause like low level of plasma estrogen and marked increase in follicle stimulating hormone levels exert a significant effect on metabolism of plasma lipids and lipoproteins leading to atherosclerosis, thereby increasing the risk of CVD in postmenopausal women.

Objectives: To study the lipid profile parameters and to calculate and compare the lipid indices with lipid profile parameters in pre- and postmenopausal women.

Materials and methods: The study group included 90 women comprising 45 postmenopausal (cases) and 45 premenopausal (control) women. To estimate lipid profile, enzymatic method was used and for calculation of lipid indices appropriate formula was used.

Results: Altered lipid profile was observed in postmenopausal women, but it was not statistically significant. Atherogenic Index of Plasma, Castelli's risk index-I, atherogenic coefficient, and nonhigh-density lipoprotein cholesterol were significantly increased in postmenopausal women compared with premenopausal women, but there was no significant increase in Castelli's risk index-II.

Conclusion: Lipid indices may be considered as a better and cost-effective tool in assessing the risk of CVD in postmenopausal women.

Keywords: Cardiovascular disease, Lipid indices, Lipid profile, Postmenopause.

How to cite this article: Sirigere M, Meera S. Novel Lipid Indices as a Better Marker of Cardiovascular Disease Risk in Postmenopausal Women. Indian J Med Biochem 2017;21(1):38-41.

Source of support: Nil

Conflict of interest: None

${ }^{1}$ Postgraduate Student, ${ }^{2}$ Professor and Head

1,2Department of Biochemistry, Mysore Medical College and Research Institute, Mysuru, Karnataka, India

Corresponding Author: Muruga Sirigere, Postgraduate Student, Department of Biochemistry, Mysore Medical College and Research Institute, Mysuru, Karnataka, India, Phone: +919620139932, e-mail: sirigeremax15@gmail.com

\section{INTRODUCTION}

The occurrence of atherosclerosis is less frequent in premenopausal women than in postmenopausal women. This is because of derangement of lipid profile which increases the risk of cardiovascular disease (CVD) in postmenopausal women. ${ }^{1}$ Data from the Framingham study suggest that coronary artery disease (CAD) morbidity rate increases more rapidly in females than those of males after the age of 45 years. $^{2}$ A larger proportion of women $(52 \%)$ than men $(42 \%)$ with myocardial infarction die of sudden cardiac death before reaching the hospital. ${ }^{3}$

The World Health Organization defines menopause as "the permanent cessation of menstruation as a result of the loss of ovarian activity." ${ }^{4}$ It is usually a natural transition which occurs in women in their late forties and early fifties, signaling the end of the fertile phase of women's life. In India, the median age of natural menopause is considerably earlier at 44 years. ${ }^{5}$

According to the various studies, women who underwent surgical menopause or had premature menopause showed increased prevalence of CAD and in whom plasma cholesterol levels and triglyceride (TG) levels are consistently increased after menopause. ${ }^{6,7}$ A decrease in high-density lipoprotein (HDL) level and increase in low-density lipoprotein (LDL) level in postmenopausal women may be attributed to the cause of increased atherosclerotic heart disease.

Lipid profile estimation is considered as one of the standard tests to assess the risk of CVD. In the absence of abnormal lipid profile, the possibility of CVD cannot be ruled out. Various parameters of lipid indices have been studied to be sensitive risk markers of CVD and, moreover, lipid indices are calculated using formulas that can be used in all health sectors without the burden of cost-effectiveness. Hence, this study has been undertaken on the role of various lipid indices like Atherogenic Index of Plasma (AIP), Castelli Risk Index I and II (CRI-I and CRI-II), non-HDL cholesterol (NHDL-C), and atherogenic coefficient (AC) in assessing the risk of CVD in postmenopausal women with the following objectives. 


\section{OBJECTIVES}

To study the lipid profile parameters, and to calculate and compare the lipid indices with lipid profile parameters in pre- and postmenopausal women.

\section{MATERIALS AND METHODS}

The study was carried out in the Department of Biochemistry in association with the Obstetrics and Gynecology Department of our institution. Prior informed consent for collection of sample was taken from all the study subjects. Ethical clearance was obtained from the Institutional Ethical Committee. The total number of study subjects was 90 . Based on the following inclusion and exclusion criteria, the cases and controls were considered for the study.

\section{Inclusion Criteria}

- Forty-five confirmed postmenopausal women attending the gynecology outpatient department were included in the study as cases.

- Forty-five regular menstruating premenopausal women were included in the study as controls.

\section{Exclusion Criteria}

- Known case of hypertension, obesity, diabetes mellitus, CVD, hepatic, metabolic and renal disease, any neoplasia, arthritis or any other inflammatory disease, and those who are on hormone replacement therapy or lipid-lowering drugs were excluded from the study.

\section{Collection of Blood Samples}

After getting informed consents from the subjects, $5 \mathrm{~mL}$ of blood was collected in a red plain vacutainer tube devoid of anticoagulant under aseptic condition from the subjects after overnight fasting of 12 to 14 hours. This, however, was done after the 7 th day of the last menstrual period for premenopausal group.

Samples were centrifuged at 3,000 rpm to separate serum within 1 hour and the following lipid profile parameters were estimated:

- Serum total cholesterol (TC) by enzymatic Cholesterol oxidase- Phenol and 4 Aminoantipyrine method.

Table 1: Lipid profile of pre- and postmenopausal women

\begin{tabular}{lllll}
\hline & $\begin{array}{l}\text { Premenopausal } \\
\text { women (mean } \pm \\
\text { SD) }\end{array}$ & $\begin{array}{l}\text { Postmenopausal } \\
\text { women (mean } \\
\pm S D \text { ) }\end{array}$ & t-value & p-value \\
\hline TC & $161.54 \pm 32.72$ & $178.81 \pm 56.22$ & 1.76 & 0.086 \\
HDL & $46.94 \pm 14.61$ & $43.13 \pm 13.2$ & 1.32 & 0.212 \\
LDL & $95.21 \pm 30.71$ & $105.91 \pm 42.6$ & 1.34 & 0.18 \\
VLDL & $21.84 \pm 10.87$ & $27.93 \pm 17.44$ & 1.80 & 0.08 \\
TG & $109.65 \pm 54.08$ & $139.65 \pm 87.23$ & 1.72 & 0.088 \\
\hline
\end{tabular}

Values are measured in $\mathrm{mg} / \mathrm{dL}$
- Serum TG by enzymatic Glycerol phosphate oxidase- 4 chlorophenol and 4-Aminophenazone method.

- Serum HDL cholesterol by direct method.

- Serum LDL cholesterol by Friedwald's formula: [(TC HDL) TG/5].

- Very low density lipoprotein (VLDL) cholesterol by TG/5.

Lipid indices were calculated using the following formulas:

- $\mathrm{AIP}=\log (\mathrm{TG} / \mathrm{HDL})^{8}$

- $\quad \mathrm{CRI}-\mathrm{I}=\mathrm{TC} / \mathrm{HDL}^{9-11}$

- $\quad$ CRI-II $=$ LDL $/ \mathrm{HDL}^{9-11}$

- $\mathrm{AC}=(\mathrm{TC}-\mathrm{HDL}) / \mathrm{HDL}^{12}$

- $\mathrm{NHDL}-\mathrm{C}=\mathrm{TC}-\mathrm{HDL}^{12}$

\section{Statistical Method}

Descriptive statistical analysis has been carried out in the present study. Results on continuous measurements are presented as mean \pm standard deviation (SD) and results on categorical measurements are presented as number (\%). Significance is assessed at 5\% level of significance. Student's t-test (two-tailed, independent) has been used to find the significance of study parameters on continuous scale between the two groups.

\section{RESULTS}

Table 1 depicts the lipid profile of pre- and postmenopausal women. The values of TC, LDL, VLDL, and TG were increased, and HDL values were decreased in postmenopausal women when compared with premenopausal women. However, these values are not statistically significant.

Table 2 represents the various lipid indices in pre- and postmenopausal women. The parameters AIP, CRI-I, AC, and NHDL-C show statistically significant results in postmenopausal when compared with premenopausal women, but CRI-II did not show statistically significant results.

\section{DISCUSSION}

In our study, there is an increase in the mean values of TC, TG, LDL and decrease in HDL levels in postmenopausal

Table 2: Lipid indices in pre- and postmenopausal women

\begin{tabular}{lllll}
\hline & $\begin{array}{l}\text { Premenopausal } \\
\text { women (mean } \\
\pm S D \text { ) }\end{array}$ & $\begin{array}{l}\text { Postmenopausal } \\
\text { women (mean } \\
\pm S D \text { ) }\end{array}$ & t-value & $p$-value \\
\hline AIP & $0.01 \pm 0.29$ & $0.12 \pm 0.28$ & 2.06 & 0.041 \\
CRI-I & $3.79 \pm 1.44$ & $4.47 \pm 1.81$ & 2.00 & 0.046 \\
CRI-II & $2.27 \pm 1.14$ & $2.73 \pm 1.45$ & 1.74 & 0.082 \\
AC & $2.79 \pm 1.45$ & $3.49 \pm 1.83$ & 2.07 & 0.048 \\
NHDL-C & $114.58 \pm 32.89$ & $135.68 \pm 55.77$ & 2.12 & 0.035 \\
\hline p-value $<0.05$ suggests statistical significance &
\end{tabular}


women when compared with premenopausal women. This altered lipid profile may be due to hormonal imbalance in postmenopausal women. However, these values were not statistically significant; this may be owing to reduced number of sample size. These findings of our study are in accordance with other studies done by Kalavathi et $\mathrm{al}^{13}$ and Igweh et al. ${ }^{14}$

The study done by Varu et $\mathrm{al}^{15}$ and Shinde et $\mathrm{al}^{16}$ showed that mean levels of TC, TG, and LDL were significantly higher in postmenopausal women and these levels significantly increased with increase in duration of menopause. While the levels of HDL were significantly lower in postmenopausal women, these levels were significantly decreased with increase in duration of menopause.

In the absence of traditional risk factors like in the present study, with statistically insignificant TC, LDL, VLDL, and TG levels, chances of none identifying the risk of CAD will be more. In such scenario, there is need for some special tests that are required to be analyzed as risk factor of CVD. Such special tests are lipoprotein(a), plasma homocysteine, and small dense, undesirable type of LDL. These special tests may not be feasible in all health care centers as it is more cost-effective, lack of facilities, and insufficient resources. Hence, the calculated lipid indices play a significant role as risk factors for CVD in postmenopausal women.

In our study, we have observed that there is a statistically significant result obtained in AIP, CRI-I, AC, and NHDL-C among postmenopausal women when compared with premenopausal women. Studies done by Gaziano et $\mathrm{al}^{17}$ and Dobiášová ${ }^{18}$ showed that AIP is a strong predictor of myocardial infarction. In the present study, AIP is statistically significant in postmenopausal women, indicating a better marker. Studies by Nwagha et $\mathrm{al}^{19}$ have shown that in situations where TG and HDL appear normal, AIP may be the diagnostic alternative and CRI-II was not statistically significant. The results of our study are in accordance with studies conducted by Siddiqui et $\mathrm{al}^{20}$ and Mannangi et al. ${ }^{21}$ In this study, though lipid profile values were increased in postmenopausal women, the values were not statistically significant, but lipid indices showed statistically significant results. This indicates that lipid indices may be used as a better marker to assess the risk of CVD.

\section{CONCLUSION}

From the current study, lipid indices seem to be the preferred parameter to assess the risk of CVD in postmenopausal women when compared with lipid profile. The lipid profile parameters can be used to derive these lipid indices in centers where there is limited availability of new and special markers and specialized equipments. Thus, the use of these lipid indices can be introduced as a routine parameter in complement with lipid profile in identifying high-risk individuals for CVD and drug management.

\section{REFERENCES}

1. Kannel WB, Hjortland MC, McNamara PM, Gordon T. Menopause and risk of cardiovascular disease: the Framingham study. Ann Intern Med 1976 Oct;85(4):447-452.

2. Lerner DJ, Kannel WB. Patterns of coronary heart disease morbidity and mortality in the sexes: a 26 year follow-up of the Framingham population. Am Heart J 1986 Feb;111(2): 383-390.

3. Murphy SL. Deaths: final data for 1998. Natl Vital Stat Rep 2000 Jul;48(11):1-105.

4. Despande A, Patil S, Manjunatha A, Bagali S, Banu G. Study of atherosclerotic risk factors in postmenopausal women. Intern J Biomed Adv Res 2012;3(8):645-647.

5. Ringa V. Menopause and treatments. Qual Life Res 2000 Jan;9(Suppl 1):695-707.

6. Spitzer RS, Lee KT, Thomas WA. Early age of menopause in young women with acute myocardial infarction. Am Heart J 1957 Jun;53(6):805-808.

7. Oliver MP, Boyd GS. Effect of bilateral ovariectomy on coronary artery disease and serum lipid levels. Lancet 1959 Oct;2(7105):690-694.

8. Dobiášová M. Atherogenic index of plasma [log (TG/HDLcholesterol)]: theoretical and practical implications. Clin Chem 2004 Jul;50(7):1113-1115.

9. Stampfer MJ, Sacks FM, Salvini S, Willett WC, Hennekens CH. A prospective study of cholesterol, apolipoproteins, and the risk of myocardial infarction. N Engl J Med1991 Aug;325(6): 373-381.

10. Ridker PM, Stampfer MJ, Rifai N. Novel risk factors for systemic atherosclerosis: a comparison of $\mathrm{C}$-reactive protein, fibrinogen, homocysteine, lipoprotein(a), and standard cholesterol screening as predictors of peripheral arterial disease. JAMA 2001 May;285(19):2481-2485.

11. Castelli WP, Abbott RD, McNamara PM. Summary estimates of cholesterol used to predict coronary heart disease. Circulation 1983 Apr;67(4):730-734.

12. Brehm A, Pfeiler G, Pacini G, Vierhapper H, Roden M. Relationship between serum lipoprotein ratios and insulin resistance in obesity. Clin Chem 2004 Nov;50(12):2316-2322.

13. Kalavathi L, Dhruvanarayan HR, Zachariah E. Plasma estradiol and lipid profile in perimenopausal women. Indian J Physiol Pharmacol 1991 Oct;35(4):260-262.

14. Igweh JC, Nwagha UL, Okaro JM. The effects of menopause on the serum lipid profile of normal females of South East Nigeria. Niger J Physiol Sci 2005 Jun-Dec;20(1-2):48-53.

15. Varu MS, Vegad AM, Jani HA, Savalia CV, Joshi VS. A comparative study of serum lipid profile between premenopausal and postmenopausal women. NJIRM 2012 Jan-Mar;3(1): 43-45.

16. ShindeSS, Bimanpalli MV, Apte IC, Mahajan VV, Narkhede HP. Study of lipid profile and $C$ reactive protein in pre and postmenopausal women. J Clin Diagn Res 2011 Dec;5(8): 1544-1547. 
17. Gaziano JM, Hennekens CH, O’Donnell CJ, Breslow JL, Buring JE. Fasting triglycerides, high density lipoprotein, and risk of myocardial infarction. Circulation 1997 Oct;96(8): 2520-2525.

18. Dobiášová M. AIP-atherogenic index of plasma as a significant predictor of cardiovascular risk: from research to practice. Vnitr Lék 2006 Jan;52(1):64-71.

19. Nwagha UI, Ikekpeazu EJ, Ejezie FE, Neboh EE, Maduka IC. Atherogenic index of plasma as useful predictor of cardiovascular risk among postmenopausal women in Enugu, Nigeria. Afr Health Sci 2010 Sep;10(3):248-252.

20. Siddiqui IA, Laxmikanth B, Mariya, Rama Rao J. Lipid indices in type II diabetes mellitus and their association with micro and macro vascular complications. Int J Med J Res Health Sci 2013 Jan-Mar;2(1):87-92.

21. Mannangi NB, Jayaram S, Virupaksha HS, Kashinakunti S, Manjula R. Novel lipid indices in chronic kidney disease. Natl J Med Res 2015 Jan-Mar;5(1):39-42. 